\title{
Optimization of the Design of a Spark Plug with an Integrated Chamber for Combustion of Prepared Homogeneous Mixtures in the Cylinder of a Current Spark-ignition Engine (SPWIC Optimization)
}

\author{
Radek Procházka
}

\begin{abstract}
This article deals with a new embodiment of spark plugs with an integrated chamber called SPWIC. The earlier engines had spark plugs made with the M14x1,25 threaded spark plug housing. With this thread, the plug is screwed into the chamber in the cylinder head of the combustion engine. The problem is that the currently produced motors have chambers in the cylinder head of the internal combustion engine only adapted to spark plugs with the M12x1,25 thread spark plug housing. My work is based on the complete design of the spark plug with integrated SPWIC chamber for contemporary spark ignition engines with spark plug housing M12x1,25 in 3D software AutoCAD Inventor Professional. These plugs should be produced in cooperation with the largest producer of spark plugs in the Czech Republic by BRISK a.s. Tábor. Subsequently, these plugs will be tested on test engines of the combustion engines at the Department of Vehicle and Engine, Technical University of Liberec, on the 1.6MPI series EA211 from the VW Group.
\end{abstract}

Keywords - Design, Ignition the prepared homogeneous mixture, spark-ignition engine, spark plug with integrate chamber SPWIC

\section{INTRODUCTION}

The research project spark plug with integrate chamber (in the shortcut SPWIC) to ignite the homogeneous mixture produced in the engine cylinder began to be solved in the laboratory of power units of vehicle and engine at the Faculty of Mechanical Engineering of the Technical University in Liberec, Czech Republic (KVM FS TUL) in 2002 under the responsible investigator prof. Ing. Stanislav Beroun CSc. And continues to the Department of Vehicles and Engines of the Institute for Nanomaterials, Advanced Technologies and Innovations of the Technical University of Liberec (CxI Laboratories). The first results, which were unexpectedly optimistic, helped to establish cooperation (technical and production assistance for special parts for SPWIC) with the most famous and largest manufacturer of spark plugs in the Czech Republic and the company BRISK a.s. Tábor.

In 2014 we were terminated optimization of construction

Radek Procházka , PhD Student, Department of Vehicles and Engines, Technical University of Liberec, Czech Republic
SPWIC with extensive experimental verification SPWIC properties and their effect on the course of ignition and burn-mixture in the cylinder by measuring the functional SPWIC samples on the test engine. Functional samples spark plugs with integrate chamber were produced in cooperation with the manufacturer of spark plugs BRISK a.s. Tábor. For measurement on the test engine, standard measuring and testing techniques were used, so the above-standard technical equipment of the Laboratory of the Department of Vehicles and Engines of the Faculty of Mechanical Engineering (Department of Vehicles and Motors of the Institute for Nanomaterials, Advanced Technologies and Innovations) of the Technical University of Liberec. All measured modes included a high-pressure indication (in all engine cylinders) with thermodynamic analysis of measured pressured waveforms in cylinders and statistical evaluation of parameters of the working cycle of the engine parameters and burning at ignition of the mixture.

The research program with SPWIC in 2015 and 2016 included further design work on SPWIC with extensive experimental verification of the possible optimization of the operational adjustment of the engine with SPWIC. In selected modes, a burnout visualization was performed in the engine cylinder. The spark plug with integrated chamber has been filed for patenting and registered as a utility model

\section{THEORY}

The combustion of the mixture in the cylinder (combustion chamber) of the engine has a decisive influence on the parameters of the working cycle and the operating characteristics of all piston combustion engines (PSM). In addition to the physical quantities that describe the burning process (start of combustion, burning rate, total burning time, temperatures and pressures in the cylinder), the stability of the course of the combustion process (repeatability and reproducibility of the above-mentioned physical quantities) in the individual operating cycles of the engine is also important for the parameters of the working cycle. In spite of the very detailed clarity of the conditions for the start and the subsequent ignition of the spark-ignition engines (a homogeneous mixture 
ignited by a high voltage discharge on the spark plug electrodes) compared to compression-igntion engines feature spark-ignition engines have great variability of combustion processes in the engine cylinder, which is manifested by considerable variation of cylinder pressure between individual engine operating cycles. The causes of this inter-cycle variance are given by the differences in initiation energy and its distribution in the combustion space at the start of combustion. The spark-ignition engine has initiating energy of $10-40 \mathrm{~mJ}$ in a single focal point of the ignition (in the space between the electrodes). On the other hand, in the case of a compression-ignition engine, the initiation of combustion is initiated by the energy of $100-200 \mathrm{~J}$, when the energy is distributed to a considerable number of ignition points over the entire volume of combustion space. The great variability in ignition engine operating cycles has a significant negative effect on the performance of the spark-ignition engines (it impacts overall engine efficiency, complicates engine tuning in terms of optimization and availability of power and emission parameters). The rate of combustion (the rate of heat release $\mathrm{dQ} / \mathrm{d} \cdot$ ) at the very beginning, i.e. in the focal point (or focal point) of the burning, is decisive for the variability of the working cycles. Computational simulations as well as thermodynamic analysis of the measured flow chart of the spark-ignition and compression-ignition engines indicate that this initial rate of heat release in spark-ignition engines with a cylinder volume of $2 \mathrm{dm} 3$ (spark-ignition engines for gas fuel) with a classic spark ignition is in units $\mathrm{J} / \mathrm{deg}$. On the other hand, in the case of performance and dimensionally comparable compression-ignition engines, the start of combustion $d Q / d$. reaches tens to hundreds of $\mathrm{J} / \mathrm{deg}[1]$.

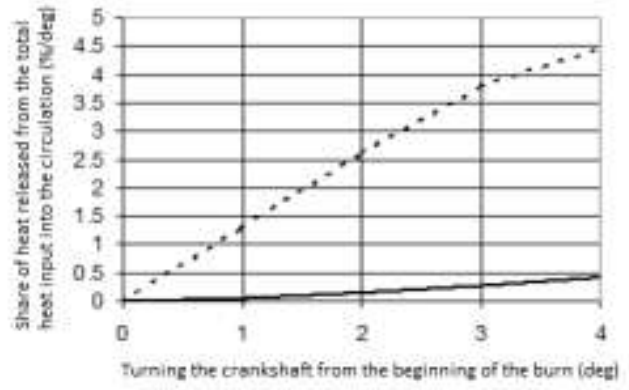

Fig. 1. Comparison of spark-ignition engine (full line) and compression-ignition engine (dashed)- for a petrol engine, a single focus cannot provide a higher burn rate [2].

In the Fig. 1. is a comparison of the initial burning speeds of a spark-ignition and a compression-ignition engine, expressed by the amount of released heat, wherein the compression-ignition engine has a higher initial firing rate.

The problem of spot ignition of the homogeneous mixtures prepared for all types of spark-ignition engines (both liquid and gaseous fuels) is devoted great attention to the development of internal combustion engines from the very development of spark ignition engines. In terms of time during the entire combustion in the internal combustion engine is particularly problematic slow start combustion of the single focus. The initialization of the combustion is complicated and due to the variability of the conditions near the spark gap (centre and ground electrodes) of spark plugs, which influence the formation and development of the ignition. Dilution of pre-oxidation reaction products turbulence at the spark plug can be considered as the most frequent negative influence. The concept of "chamber ignition" has been working in the past for the sparking of very poor mixes in the cylinder of gas stationary engines.

The concept of "chamber ignition" has been working in the past for the sparking of very poor mixes in the cylinder of gas stationary engines. In some cases, the ignition chamber was equipped with a special supply of a certain amount of gaseous fuel directly into the chamber. The research project of the "chamber ignition" of "burst out" burning mixture from the chamber was from the beginning focused on spark-ignition engines with the external formation of stoichiometric mixtures. The design of the ignition chambers has been built from the outset to fill the chamber with a fresh mixture from the engine cylinder at the compression stroke (i.e. without a separate fuel supply to the chamber) [1].

Initial results confirmed that there is a significant potential in the ignition mode of the homogeneous mixture produced in the engine cylinder, with real possibilities for further improvement of the parameters of the current spark-ignition engines. The variation of cylinder pressure variations (so-called inter-cycle variability) of the spark-ignition engine with standard ignition and chamber ignition can be seen in Fig. 2 [2].

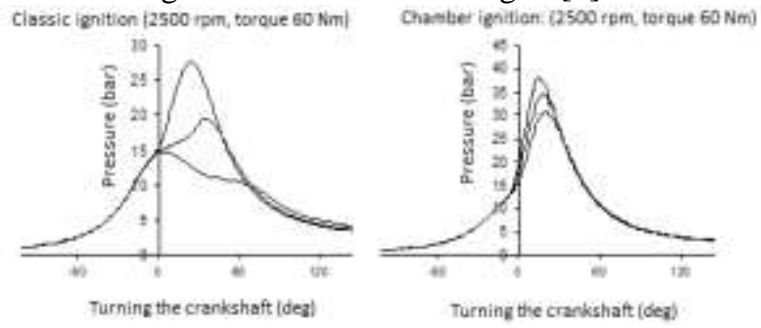

Fig. 2. Comparison of pressure of spark-ignition engine (the stroke volume of one cylinder $0,35 \mathrm{dm} 3$, homogeneous mixture prepared, lambda mixing ratio air/fuel 1, electronic control) standard ignition with a classic spark plug and ignition with a spark plug with integrated chamber (chamber volume $1,65 \mathrm{~cm} 3$, into a chamber from the cylinder during compression) [2].

In Fig. 3. is comparison mean values during the burning of the cylinder charge for the modes of Fig. 2.

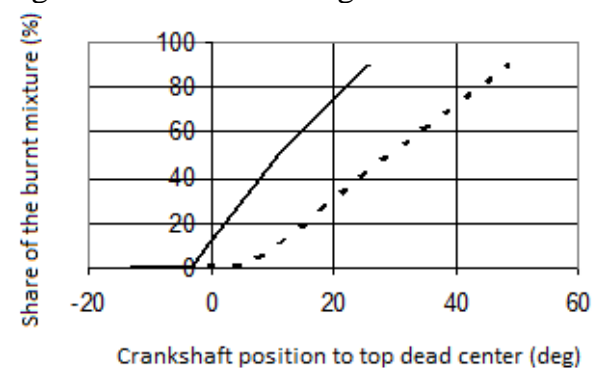

Fig. 3. Running of combustion in the engine cylinder at spark ignition with a classic spark plug (dashed) and chamber ignition (solid line). The parameters of the burning parameters are determined by thermodynamic analysis of the measured pressure and statistical processing of the burning parameters from the same measurement set as the pressure curves in Fig. 2 [2]. 


\section{SOLVED PROBLEMATICS}

Individual design variants of SPWIC (spark plugs with integrated chamber) since the beginning of the research project:

\section{A. Version for the year 2006-2014}

Spark plug with integrated chamber with an internal chamber volume of $0,6 \mathrm{~cm} 3$. The SPWIC housing was dimensionally identical to the classic spark plug (SP) housing, the lower part was closed with a bottom with a central hole about diameter 1,8 $\mathrm{mm}$. For better protection from high temperatures, the SPWIC housing was made of heat-resistant material 17022 (the classic SP has a housing made of conventional structural steel 11110 ). Extending the centre electrode to the central opening of the bottom of the chamber was a platinum wire of diameter $0,5 \mathrm{~mm}$.

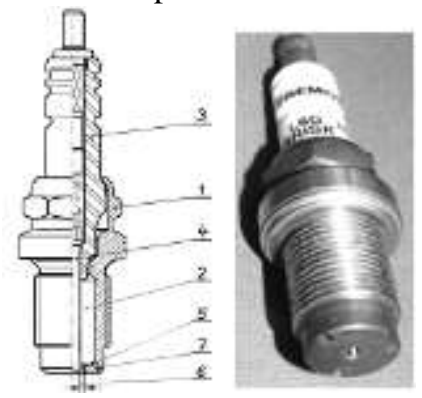

Fig. 4. Version SPWIC for the year 2006-2014 [4].

\section{B. Version for the year 2014}

SPICH with an internal volume of $0,95 \mathrm{~cm} 3$. SPICH housing made of 11110 in BRISK a.s. Tábor, the ground electrode in the central bottom opening was formed by welding a ring of heat-resistance material (laser welding). The casing was finished with a finish. Two holes were drilled with diameter $0,45 \mathrm{~mm}$ for temperature measurements in the lower part of the SPWIC housing. Several variants SPWIC were produced in embodiment SPWIC-A, SPWIC-B and SPWIC-C. In versions SPWIC-A and SPWIC-B, in addition to the central opening in the bottom of the housing, there were another 3 holes with diameter 1,65 mm, in housing of variant SPWIC-C there was only a central opening in the bottom of the housing. After the measurement was SPWIC-A modified on SPWIC-D option by chamfering the edge $0,5 \times 45^{\circ}$ on the central opening with diameter $4,4 \mathrm{~mm}$. Insulator with elongated electrode about diameter $2,7 \mathrm{~mm}$.

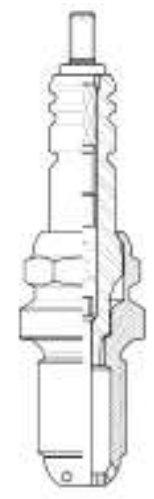

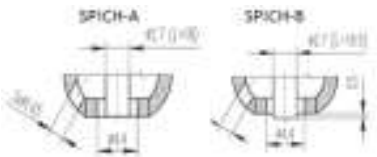
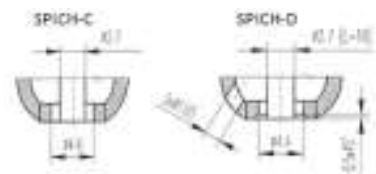

Fig. 5. Versions SPICH for the year 2014 [4].

\section{Version for the year 2015}

Experimental research on the test engine with SPWIC-B:

- Optimization of spark ignition (measurement with an open control unit with the possibility of on-line adjustment of ignition advance to achieve optimal pressure pattern in the engine cylinder).

- Visualization of the development of combustion in the engine cylinder

Experiments with different spark gap design at SPWIC (study of high voltage discharge in the BRISK a.s. Tábor pressure chamber). For further experimental research of the SPWIC on the test engine in 2015, production housing of a spark gap similar to the type of SPWIC-D (without insertion of the centre electrode) and the centre electrode recess in the center hole of the bottom of the chamber $1 \mathrm{~mm}$ (see Fig. 6.) were modified. The final assembly of SPWIC was carried out at BRISK a.s. Tábor.

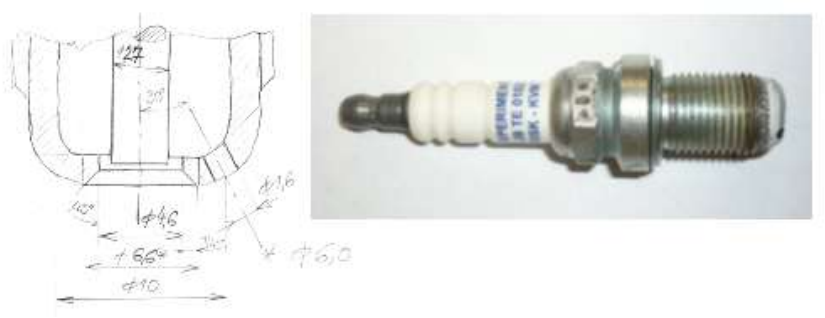

Fig. 6. Version SPWIC for the year 2015 [4.]

D. Version for the year 2016-2017

Experimental research on a test engine: measurement with SPWIC (2015), detailed analysis of high-pressure indication data. Visualization of the development of a spark ignition in the engine cylinder. Adjustment of the SPWIC-C by addition of the outlets and chamfering edges at the front of the central hole about diameter 4,6 mm on the SPWIC-E version (see Fig. 7.) [3] [4] [5].

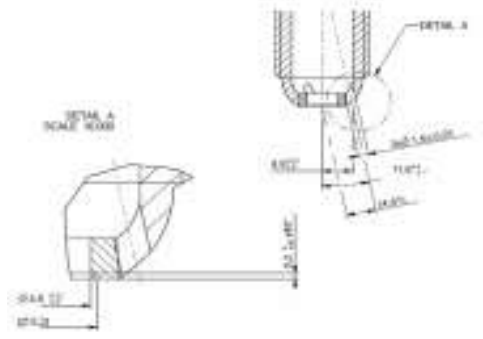

Fig. 7. Version SPWIC for the year 2016-2017 [4].

\section{E. Actual version for the year 2018}

At present, the production, testing and further development of a spark plug with integrated chamber with thread M14x1,25, because it started working on version SPWIC for contemporary spark-ignition engines, which are adapted to the spark plug with thread on the housing M12x1,25. This reduction was made by the manufacturers of combustion engines for many reasons and 
aspects. Especially changes related with current trend so called "downsizing trend" - reducing engine volume while maintaining or increasing performance using supercharging (turbocharging, compressor). These changes result in a diminishing of the individual parts of the whole combustion engine. This is also related to the effort to place as many equipment as possible on the engine (multiple intake and exhaust valves, more sophisticated injectors, distribution, cooling, lubrication, etc.)

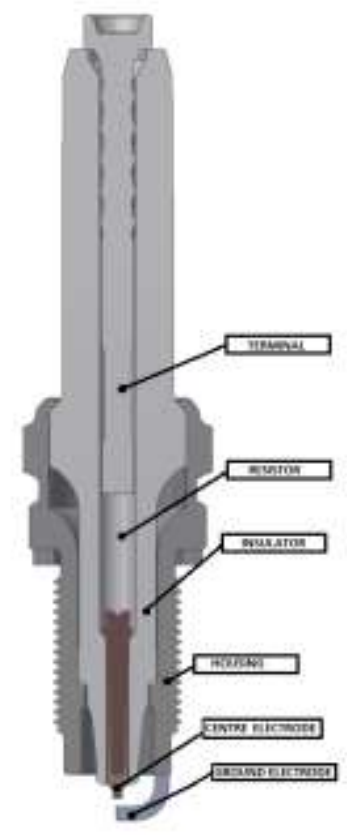

Fig. 8. Classic spark plug chamber (SP)

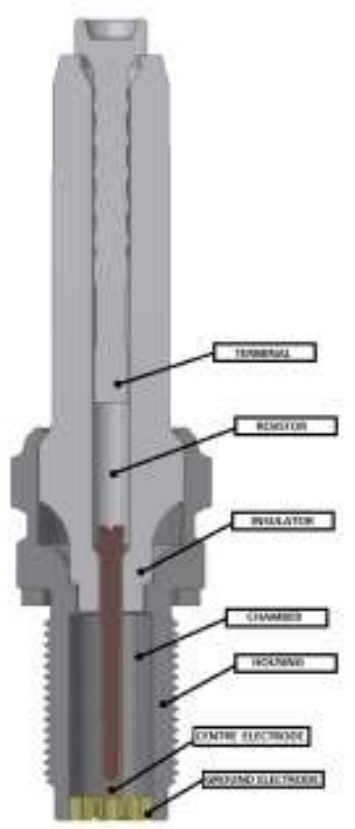

Fig. 9. Spark plug with integrated (SPWIC)
To construct a spark plug with integrated chamber with M12x1,25 thread on the housing, I approached from many aspects already verified and tested from previous research. I originated from the design of the classic spark plug from BRISK a.s. Tábor (see Fig. 10) for modern engines TSI (Twincharched Stratified Injection) a MPI (Multi Point Injection) of the EA211 series, VW Group. I created two versions of SPWIC M12x1,25, SPICH version I. with a centre electrode ending at the center of the ground electrode exactly $1 \mathrm{~mm}$ from the bottom of the housing (see Fig. 11). SPWIC version II. (see Fig. 112) with a centre electrode ending at the edge of the ground electrode exactly $2 \mathrm{~mm}$ from the bottom of the housing.

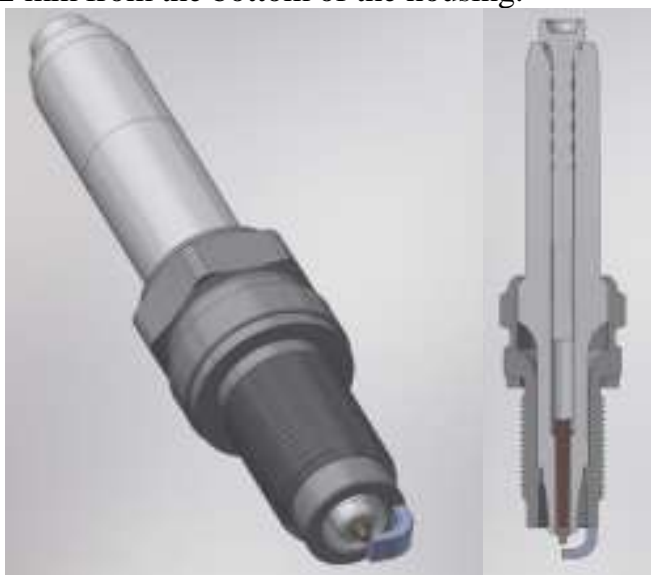

Fig. 10. Classic spark plug (SP) from BRISK a.s. Tábor

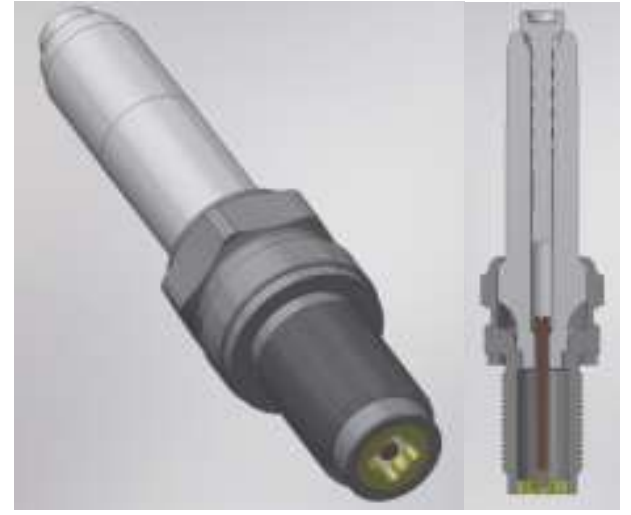

Fig. 11. Spark plug with integrated chamber version I. (SPWIC-version I.)

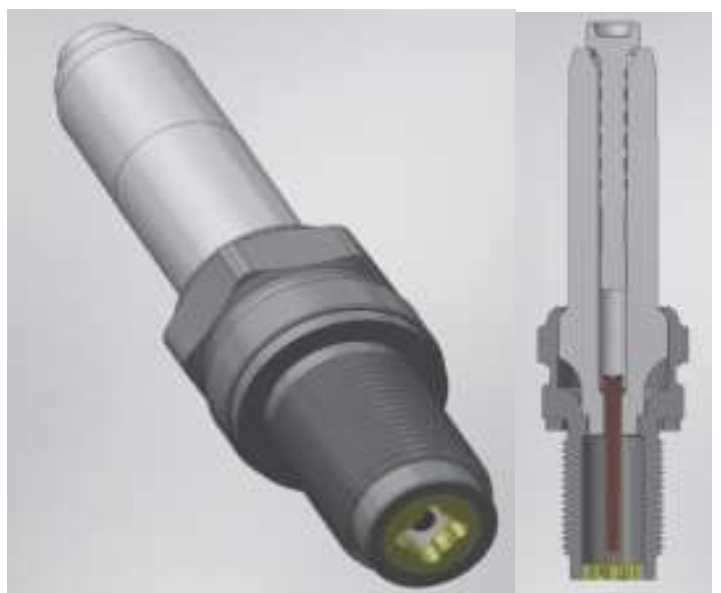

Fig. 12. Spark plug with integrated chamber version II. (SPWIC-version II.)

From the previous measurements on different versions of SPWIC, it was found that for the good functioning of the spark plug, the internal volume of the ignition chamber should be between $0,6-0,8 \mathrm{~cm} 3$. The solution with this volume of the chamber and the centre electrode extending into the opening in the bottom of the ignition chamber has proved to be the best for the reliable operation of the chamber spark plug. When it managed to improve the mixture's ignition in low-load modes, and ensured reliable engine running in idle engine mode. Regarding the burning process, the relatively low variability of the indicated mean effective pressure (IMEP) and the maximum pressure in the engine cylinder was demonstrated. The spark plug with integrated chamber with extended centre electrode in the bottom of the housing proved to be the best option in terms of engine performance and emissions.

When designing SPWIC M12x1,25, I came out of these verified properties. I have encountered a number of problems, both manufacturing and design, which have limited me against to SPWIC version M14x1,25. The main problem was that the individual parts of the spark plug (housing, insulator and terminal) had to be smaller than the SPWIC version M14x1,25. In particular, it has been a problem to achieve a chamber of spark plug volume of at least $0,6 \mathrm{~cm} 3$. Seat in the housing for accommodating the insulator has been moved further upwards. As a result, the insulator has been shortened (the insulator tip has been shortened), and the centre electrode seat has also been moved upwards. The resultant volume of the ignition chamber 
was approximately $0,7 \mathrm{~cm} 3$ for actual version SPWIC. Both versions of SPWIC, both version I. and version II., have the same identical parts as terminal and insulator. The housing differs only in the bottom where the laser-welded ground electrode is of refractory material. In version I., the ground electrode has a central hole of $3,5 \mathrm{~mm}$ in diameter versus version II., which has a hole of $3,7 \mathrm{~mm}$ in diameter. Versions have different holes to keep the maximum skip distance between the electrodes (centre and ground electrode) of $0,9 \mathrm{~mm}$. Both versions have four radial holes with a longitudinal axis of the spark plug, these holes being elongated to the central opening. Generally, I was limited by the length of the centre electrode, which can be produced at a maximum length of $27 \mathrm{~mm}$ with a diameter of $2 \mathrm{~mm}$. For version I (centre electrode ends directly at the centre of the ground electrode), the length of the centre electrode is $25,3 \mathrm{~mm}$, whereas for version II. (the centre electrode ends at the inner edge of the ground electrode), the electrode length is $24,3 \mathrm{~mm}$.

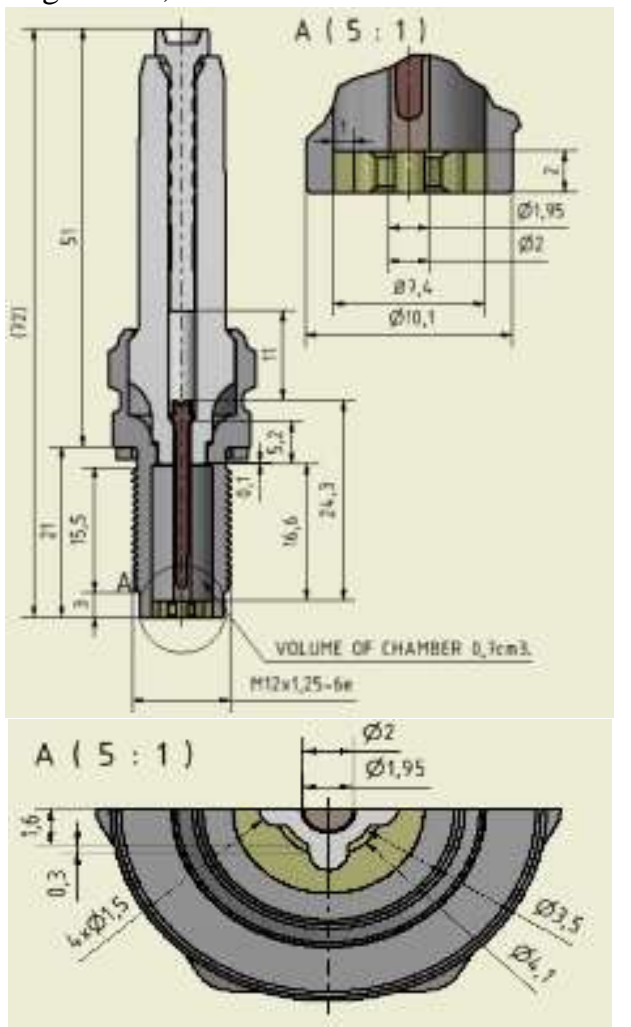

Fig. 14. Detailed drawings SPWIC M12x1,25 version II.with a centre electrode ending at the edge of the ground electrode exactly $2 \mathrm{~mm}$ from the bottom of the housing. (SPWIC-version II.)

\section{CONCLUSION}

In this article, I mentioned a new embodiment of the integrated chamber spark plug (SPWIC) with a spark plug housing with M12x1,25 thread. My work consisted of a complete design of a spark plug with an integrated chamber, including drawing documentation and contact with the manufacturer of spark plugs BRISK a.s. Tábor. At present, the SPWIC M12x1,25 spark plug (both versions I and II) are manufactured by the manufacturer and will be delivered soon. Subsequently, thorough tests will be carried out on the test spark-ignition engines of the Department of Vehicles and Engines, Technical University of Liberec, on the 1.6MPI series EA211 from the VW Group. The engine will work with a so-called open electronic engine control unit that allows you to set and change individual parameters. In all measured modes, a high-pressure indication (in all engine cylinders) with thermodynamic analysis of the measured cylinder pressures and statistical evaluation of engine operating parameters and burning parameters of the mixture. In selected modes, a visualization of burning in the engine cylinder will be performed. Measurements on the test engine will be carried out using both standard measuring and testing equipment and massive installation of the above-standard technical equipment of the Laboratory of the Department of Vehicles and Engines of the Faculty of Mechanical Engineering, Technical University of Liberec, Czech Republic.

\section{ACKNOWLEDGMENT}

This publication was written at the Technical University of Liberec as part of the project Institute for Nanomaterials, Advanced Technologies and Innovations of the Technical University of Liberec (CxI Laboratories) with the support of the Specific University Research Grant, as provided by the Ministry of Education, Youth and Sports of the Czech Republic in 2018.

\section{REFERENCES}

[1] HEYWOOD, J.B.: Internal Combustion Engine Fundamentals. McGraw-Hill, Inc., 1988. ISBN 0-07-028637-X.

[2] SCHOLZ, C.: Variability of combustion process of spark-ignition reciprocating engines. Dissertation thesis, Technical university of Liberec, 1998.

[3] BLAŽEK, J.: Research and development of chamber spark ignition for a vehicle engine. Dissertation thesis, Technical university of Liberec, 2008. ISBN 978-80-7372-301-9.

[4] BEROUN, S., BLAŽEK, J.: Spark Plug. Application for a European patent. European Patent Office, PS3542EP, 2008.

[5] BEROUN, S. - BLAŽEK, J.: Spatk plug. PUV 2009-21214. Certificate of registration issued 17.8.2009 under the number CZ19933U1.

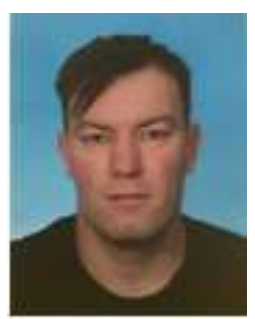

Ing. Radek Procházka was born in Jeseník, Czech Republic, in 1993. He received the B. S. degree (2014) from Technical University of Liberec and the M.S. degree (2017) in mechanical engineering from Technical University of Ostrava. He is currently pursuing the $\mathrm{Ph} . \mathrm{D}$. degree in the field of transport and handling machines at Technical University of Liberec, Specialization Pistons internal combustion engines. From 2016 to 2017, he was an development designer in 3D CAD Catia V5 in Hella Autotechnik Nova s.r.o. His research interests include thermomechanics combustion engines, testing and simulations spark-ignition engine, compression-ignition engine.

School education:

10/2017 - so far Technical University of Liberec Studentská 1402/2, 46117 Liberec 1, Czech Republic Faculty of Mechanical Engineering, Program Machines and Equipment, Field of study Transport and Handling Machines, Specialization Pistons internal combustion engines, Doctoral studies 
11th Int'I Conference on Trends in Science, Engineering, Technology \& Natural Resources (TSETWM-18) Oct. 2-4, 2018 Budapest (Hungary)

Dissertation thesis - Simulation of inter-cycle variability of the combustion process of the spark-ignition engine

$2015-2017$

Technical University of Ostrava

17. listopadu 15/2172, 70833 Ostrava - Poruba,

Czech Republic, Faculty of Mechanical Engineering, Program, Mechanical Engineering, Field of study

Transport Engineering and Technology, Specialization

Road Transport, Obtained title Ing. (engineer)

Diploma thesis - Thermodynamic analysis of internal combustion engine

$2012-2015$

Brno University of Technology, Technická 2896/2, 61969 Brno, Czech Republic, Faculty of Mechanical Engineering, Program of Engineering, Field of study Construction of Machines and Equipment, Obtained title Bc. (bachelor)

Bachelor Thesis - Safety of operation of construction machines

Work experience and practice:
2/2018 - so far Application group support in racing engine development EM - ŠKODA Motorsport, ŠKODA AUTO a.s. Václav Klementa 869, 29301 Mladá Boleslav, Czech Republic

10/2017 - so far Junior research of the vehicle and internal combustion engines laboratory, The Institute for Nanomaterials, Advanced Technologies and Innovation

Research Center of the Technical University of Liberec, Studentská 1402/2, 46001 Liberec 1, Czech Republic

7/2016 - 6/2017 Development designer in 3D CAD Catia V5 - Hella Autotechnik Nova s.r.o, Design Office of Science and Technology center in Ostrava, Technologická 372/2, 70800 Ostrava, Czech Republic

7- $8 / 2015$

Office and design work in Ondrstroj - Ondřejovická strojírna a.s., Salisov 49, 79376 Zlaté Hory, Czech Republic 